\title{
Foreign direct investment and pollution havens: evidence from African countries
}

\author{
Said Gharnit \\ Mohammed V University in Rabat, The Faculty of Law, \\ Economics and Social Sciences, Salé, Morocco \\ Mohamed Bouzahzah \\ Mohammed V University in Rabat, The Faculty of Law, \\ Economics and Social Sciences, Salé, Morocco \\ Jihad Ait Soussane \\ Ibn Tofail University, The Faculty of Law, \\ Economics and Social Sciences, Kenitra, Morocco
}

\begin{abstract}
This study examines the relationship between foreign direct investment (FDI) inflows and carbon dioxide emissions (CE) in order to investigate the validity of the pollution haven hypothesis for 54 African countries, using cointegration approach with dynamic panel data over the period 1960-2018. Based on the panel cointegration analysis, it was concluded that the variables are cointegrated. Moreover, the Dynamic Ordinary Least Square (DOLS) and Fully Modified Ordinary Least Square (FMOLS) results showed that foreign direct investment inflows have a long-run positive relationship with carbon dioxide emissions. Furthermore, according to Granger-Engle causality test results, FDI inflows and carbon dioxide emissions have a positive causal relationship, for both short-run and long-run. Thus, the results of this study validate the pollution haven hypothesis in the African countries. Nevertheless, it is recommended to keep attracting foreign direct investment inflows alongside of implementing mechanisms and instruments for reducing the $\mathrm{CO} 2$ emissions under strong environmental policies.
\end{abstract}

Keywords: Foreign direct investment; $\mathrm{CO} 2$ emissions; Pollution haven hypothesis; Panel cointegration analysis.

\section{INTRODUCTION}

During the past quarter century, foreign direct investment (FDI) have known a significant rise in flows around the world, increasing by 533\% to 1,297 billion of dollars between 1990-20181. Therefore, the FDI represents an important opportunity, especially for developing countries, to outcome their strategy for economic development, since FDI inflows contributes positively and strongly to the host country's economic growth (Fadhil and Almsafir, 2015; Nistor, 2014).

In addition of its role as a growth-enhancing factor in the developing countries (Sokang, 2018), FDI is considered to be a way to transfer new technology from other developing and especially developed countries (Melnyk et al., 2014) and also regarded as contributor in unemployment reduction by creating new job opportunities (Sharif, 2014).

1 The FDI inflows have increased from 204,88 billion of dollars in 1990 to achieve 2 033,80 billion of dollar in 2015. However, after this peak, the trend of FDI decreased in last three years to record 1297,15 billion of dollar in 2018 ("UNCTAD | World Investment Report: Annex Tables" n.d.). 
According to United Nations Conference on Trade and Development (UNCTAD) World Investment Report 2019, Africa's FDI flows enhance to 46 billion of dollars, an increase of 11\% on the prior year. Even though these flows are small by global standards, about 3.5\% of FDI flows worldwide, they remain generally steady and escaped the global decline in last three years. Moreover, the ratio of FDI to gross domestic product (GDP) reaches 5.1, makes it the highest in the world, signaling the importance of FDI to the continent's economic growth2.

Egypt remains the largest FDI recipient in the continent with $\$ 6.8$ billion, followed by South Africa with $\$ 5.3$ billion. The fastest-growing region of the continent is East-Africa where FDI flows retained stable at $\$ 9$ billion. In the other hand, FDI to Morocco remarkably increased by $36 \%$ to $\$ 3.6$ billion as a result of investments in finance and the automotive sector.

Nevertheless, the negative side of FDI flows could be the impact of the companies' activity on developing countries' environment. This leaded to a consistent debate between economists, researches and political groups generating two controversial hypotheses. First one stipulates that under the trade liberalization, the firms that produce polluting goods would move from developed countries that have strict environmental regulations to developing countries that have comparatively weak environmental regulations. Therefore, the developing countries would become pollution haven for the dirty industries of the advanced countries. This hypothesis is called pollution haven hypothesis (PHH) (Copeland and Taylor, 1994). In the other hand, the porter hypothesis $(\mathrm{PH})$ states that strict environmental regulations in home country encourage firms for investing more in clean and efficient technologies. These clean technologies reduce the marginal cost and raise the productivity, making the firms more competitive(Porter and van der Linde, 1995).

Within this context, Africa would not be excluded in this debate. Although the $\mathrm{CO} 2$ emissions in Africa represents only $3.82 \%$ of global emissions in 2017, the last quarter century recorded a sustainable raise on average of $2.8 \%$ per year making the continent the less emitting CO2 between the five major ones with 1327 megatons of carbon dioxide emissions. Understanding how this environmental advantage attract FID become necessary to predict the environmental future of the continent and establish the recommendation for a sustainable development.

In this study, we aim to investigate the validity of the pollution haven hypothesis for African countries by examining the causality between the FDI inflows and CO2 emissions. Thus, the paper is organized as follows: Section 2 provides a brief review of literature on the relationship between the evolution of FDI and the presence of PHH. Section 3 presents the data and the methodology used in this study. Section 4 summarizes the results, and finally, section 5 concludes and discusses the caveats of the research.

\section{REVIEW OF LITERATURE}

In recent decades, the debate on environmental consequences of the economic development has raised between economists and scholars resulting on many controversial hypotheses on this sphere. One of the most studied one is the Environmental Kuznets Curse hypothesis (EKC) which states that a country's pollution concentrations rise with development and industrialization up to a certain point, after which they fall again as the country uses its increased affluence to reduce pollution concentrations again (Jbara, 2007). The way to reduce the pollution concentration gives places to controversial possibilities; first one assumes that developed countries adopt cleaner technologies in the production processes (OCDE, 2002;

2(“EY’s Attractiveness Program Africa 2019” n.d.) 
Gallagher and Zarsky, 2007), the second one stipulates that developed countries would specialize in the production of clean goods while the dirty industries would be transferred to developing countries, in the form of FDI, where there is less environmental restrictions. Several case studies support this argument. As examples, Mabey and Mc Nally (1999) show that the Alena agreement strongly favored the relocation of solvent production from the United States to Mexico. In the same way, Léonard (1988) has shown that the production of dangerous, banned or highly regulated chemicals in the United States, such as pesticides, has increased dramatically in Mexico. This is the core of the pollution haven hypothesis.

As the studies on the PHH are based on different estimation methods, different dataset, different specification and also different variables, their results are mixed and cannot support nor deny the existence of the PHH. This fact leads to opposing arguments about the impacts of FDI on the environment of host countries.

Thus, to test the validity of pollution haven hypothesis and Environmental Kuznets Curve (EKC), Sapkota and Bastola (2017) explored the effects of FDI on pollution emissions using time series data from 1980 to 2014 for 14 Latin American countries. The results affirm the validity of both hypothesis for this region, also estimating two separate models for high and low-income countries does not reject the PHH. Similarly, MacDermott (2009) investigated the relationship between environment regulations and FDI by focusing on bilateral flows of aggregated FDI between 26 OECD countries from 1982 to 1997. The results showed that the firms look for countries with less environmental regulations and so the existence of PHH.

In same way, Ben Kheder and Zugravu-Soilita (2008) studied the hypothesis by applying a geographic economy model on French firm-level data, the results confirm the existence of PHH for the global sample. Through sensitivity analysis, they validated the hypothesis for Central and Eastern European countries, emerging and high-income OECD countries, but not for the major part of the Commonwealth of Independent States countries.

For the top five emitters of greenhouse gas (GHG) emissions from fuel combustibles in the developing countries, namely China, India, Iran, Indonesia and South Africa, (Sarkodie and Strezov, 2019) employed a panel data regression with Driscoll-Kraay standard error to examine the effects of FDI inflows, economic development and energy consumption on GHG emissions between 1982 and 2016. The study validated the existence of PHH for the whole sample.

Akbostanci et al. (2007), conducted their research, for Turkey between 1994 and 1997, from the trade perspective by using the panel data approach for manufacturing industries, they found that exports increase as the dirty industries as well, proving some evidence for the hypothesis. Also, for the same country, Mutafoglu (2012) inspected the relationships among FDI inflows, Carbon Dioxide (CO2) emissions, and economic growth over the period of 1987Q1-2009Q4. Through the Granger causality test, generated from the error-correction model (ECM), he demonstrated the existence of casual relationship between variables, hence, supporting the pollution haven hypothesis.

For Ghana's case, Solarin et al., 2017 used many variables as determinants of air pollution for the period of 1980-2012, the study included gross domestic product (GDP), GDP square, energy consumption, renewable energy consumption, fossil fuel energy consumption, foreign direct investment, institutional quality, urbanization and trade openness. The results support 
the existence of long-run relationship between the variables, also a positive impact on $\mathrm{CO} 2$ emissions which indicates the existence of PHH in the country.

By using a non-stationarity panel technique, Al-mulali and Foon Tang (2013) studied the impacts of FDI, energy consumption and GDP growth on CO2 emissions for the Gulf Cooperation Council (GCC) countries from 1980 to 2009. The fully modified OLS results reject a positive impact of FDI on CO2 emissions, contrary to energy consumption and GDP growth that increase $\mathrm{CO} 2$ emissions.

Furthermore Javorcik and Wei (2003) carried out their research from a different perspective, they focused on investment flows from multiple countries to 25 economies in Eastern Europe and the former Soviet Union. The aim of choosing this sample is its convenience of being lax environmental regulations and the effect of host country corruption. They also relied on firmlevel rather than industry-level data to make the study more relevant. The outcomes revealed showed no systematic evidence that FDI from dirtier industries are shifted towards countries with weak environmental regulations.

Differently, Kirkpatrick and Shimamoto (2008) explored the impact of environmental regulation in host countries on Japanese FDI decision-making for five dirty industries (iron and steel industry, nonferrous metals industry, chemicals industry, paper and pulp industry, nonmetallic products industry). The results found reject the PHH. Moreover, they revealed that inward Japanese FDI are more attracted to countries with more transparency in term of environmental regulatory measures.

\section{DATA AND EMPIRICAL MODEL}

In our paper, the precise question for the empirical framework is formulated in which the longterm relationship and causality between Foreign Direct Investment (FDI) and the emission of CO2 (CE) must be examined. The important question of research is as follows: To what extent do foreign direct investments impact the carbon emission within African countries? On the one hand, the overarching research question can be empirically tested for all countries that have important data available for both variables in both country and time dimensions. On the other hand, the subjacent questions are the methodology and the model to be adopted, the steps of empirical estimation and the description of the data.

\section{The adopted methodology}

According to a review of abundant theoretical and empirical literature, there are several channels, through which, FDI can influence carbon emission in host countries. As a result, panel cointegration analysis is not intended to isolate the effects of FDI on CE by working on specific transmission channels; on the contrary, its goal is to capture its overall effects. This provides a major argument in favor of the bivariate approach (or the two-dimensional approach) and the control of variables (such as exchange rate, infrastructure, labor productivity). Therefore, serious problems of estimation are also avoided.

\section{The empirical model}

In line with the current practice of studies using the panel cointegration approach, two bivariate models are estimated the following form:

Equation (1) presents the two-dimensional long-term relationship between FDI and CE:

$$
C E_{i t}=\alpha_{i}+\beta_{i} F D I_{i t}+\varepsilon_{i t}
$$


With $C E_{i t}$ is Carbon Emissions in a country $i$ in year $t$ (in metric tons per capita) and $F D I_{i t}$ the FDI inflows in country $i$ in year $t$ (in current US\$).

In addition, we include $\alpha_{i}(i=1,2 \ldots 54)$ the country-specific fixed effect for controlling country-specific omitted factors that are relatively stable over time.

Equation (2) presents the short-term and long-term two-dimensional causality between the FDI and the CE; this relationship can be obtained by estimating the Dynamic Error Correction Model (DECM) as follows:

$$
\Delta C E_{i t}=\alpha_{i}+\lambda_{i} \varepsilon_{i t-1}+\sum_{q} \theta_{i q} \Delta C E_{i t-q}+\sum_{q} \beta_{i q} \Delta F D I_{i t-q}+\mu_{i t}
$$

Where $q$ is the optimal lag length for each country in the panel, $\theta_{i}$ the speed of adjustment to the long-term equilibrium path, $\lambda_{i}$ the long-term effect of FDI on the CE, $\beta_{i}$ the short-term effect of FDI on the CE and $\mu_{i t}$ the error term white noise.

\section{The descriptions of the data}

To evaluate the proposal to find the impact of FDI on carbon emission within the African countries, the empirical analysis is based on panel data from 54 African countries3, between 1960 and 2018, meaning over 59 years. The data of the two variables are extracted from the database of the World Bank. The foreign direct investment is net investment income to acquire a sustainable equity interest (10\% or more of the voting shares) in an enterprise operating in an economy other than that of the investor. It is the sum of equity, reinvested earnings, other long-term capital and short-term capital recorded in the balance of payments. This series shows the net inflows (net investment flows minus disinvestments) of foreign investors in the reporting economy. Carbon dioxide emissions are those that emanate from the burning of fossil fuels and the manufacture of cement. They include carbon dioxide emissions from the consumption of solid, liquid and gaseous fuels and flaring.

\section{Testing the unit root}

\section{EMPIRICAL OUTPUTS AND RESULTS}

Before testing cointegration and proceeding to the identification of a long-run relationship, it is necessary to verify that variables are integrated in order I(0) or I(1). The purpose of the panel unit root test is to check the stationarity status of both variables in the model and to ensure that they are not integrated in order 2 or more since the results could be spurious and the ARDL approach becomes no longer applied (Omar et al., 2015).

Table 1. Panel Unit Root Test Results

\begin{tabular}{|c|c|c|c|c|c|c|}
\hline \multirow{2}{*}{ Variable } & \multicolumn{3}{|c|}{ Common unit root } & \multicolumn{3}{c|}{ Individual unit root } \\
\cline { 2 - 7 } & LLC & Breitung & Hadri & $I P S$ & ADF & $P P$ \\
\hline$C E$ & $I(0)^{*}$ & $I(0)^{*}$ & $I(0)^{*}$ & $I(0)^{*}$ & $I(0)^{*}$ & $I(0)^{*}$ \\
\hline$F D I$ & $I(0)^{*}$ & $I(0)^{*}$ & $I(0)^{*}$ & $I(0)^{*}$ & $I(0)^{*}$ & $I(0)^{*}$ \\
\hline
\end{tabular}

Note: *,**** indicate significance respectively at the level of $1 \%, 5 \%$ and $10 \%$. The maximum delay selection is automatic by the software using the SIC as a benchmark.

\footnotetext{
${ }^{3}$ Algeria, Angola, Benin, Botswana, Burkina Faso, Burundi, Cabo Verde, Cameroun, Central African Republic, Comoros, Congo, Côte d'Ivoire, Djibouti, DR Congo, Egypt, Eritrea, Swaziland, , Ethiopia, Gabon, Gambia, Ghana, Guinea, Guinea equatorial, Guinea-Bissau, Kenya, Lesotho, Liberia, Libya, Madagascar, Malawi, Mali, Morocco, Maurice, Mauritania, Mozambique, Namibia, Niger, Nigeria, Uganda, Rwanda, Sao Tomé-et-Principe, Senegal, Seychelles, Sierra Leone, Somalia, Soudan, South Africa, South Soudan, Tanzania, Chad, Togo, Tunisia, Zambia, Zimbabwe
} 
First, we start with the common unit root tests that assume the existence of homogeneity between countries. According to the three common unit root tests Levin, Lin, Chu (LLC), Hadri and Breitung, the CE and FDI variables are both stationary at the level since the null hypothesis of a common unit root is rejected at the significance level of $1 \%$. We accept the alternative hypothesis of stationarity of series. Thus, both variables, $C E$ and $F D I$, are integrated in the order of zero $\mathrm{I}(0)$ at the risk threshold of $1 \%$.

Now, we admit the existence of heterogeneity between countries. According to the three individual unit root tests Im, Pesaran and Shin (IPS), Augmented Dickey-Fuller (ADF) and Philipe-Perron (PP), the variables $C E$ and FDI are still stationary at the level since the null hypothesis of an individual unit root is rejected at threshold of $1 \%$ and we accept the alternative hypothesis of series stationarity. Hence, both variables are integrated in the order of zero $\mathrm{I}(0)$ at the risk threshold of $1 \%$.

\section{Testing the cointegration of the panel}

The next step is supposed to be the cointegration between the two variables using two tests, ARDL Bound and Fisher (Johansen Combined).

Table 2. Panel Cointegration Test Results

\begin{tabular}{|c|c|c|}
\hline \multirow{3}{*}{ ARDL Bound test } & None & Constant \\
\cline { 2 - 3 } & -0.808443 & -0.949920 \\
& $(0.0000)^{*}$ & $(0.0000)^{*}$ \\
\hline Fisher & Trace & Max-eigen \\
\cline { 2 - 3 } (Johansen Combined) & COI $\leq 1^{*}$ & COI $\leq 1^{*}$ \\
\hline
\end{tabular}

Note: $*, * * * * *$ indicate significance respectively at the level of $1 \%, 5 \%$ and $10 \%$. The maximum delay selection is automatic by the software using the SIC as a benchmark.

After verifying that the two variables are integrated in I(0), the Fisher, Trace and Max-Eigen tests, based on the Johansen methodology, allow us to test the cointegration between these variables. First, Fisher's two tests reject the null hypothesis of non-cointegration between the $C E$ and FDI variables at the $1 \%$ threshold and accept the alternative hypothesis that these variables are cointegrated. In addition, both tests cannot reject the null hypothesis that there is more than one cointegration relationship. Then, one could conclude, according to Fisher's two tests, that the variables $C E$ and $F D I$ are cointegrated namely the existence of a long-term association.

The ARDL Bound test confirms the results obtained by the two Fisher tests, namely the rejection of the null hypothesis of non-cointegration between $F D I$ and $C E$ at the significance level of $1 \%$ for the two trend specifications.

According to the two cointegration tests, ARDL bound and Fisher (Johansen Combined), the $C E$ and FDI variables are cointegrated and associated in the long term, any estimate of the impact would be robust and reliable while avoiding a regression misleading.

\section{Estimating the long-term parameters}

Based on the above results, we estimate the long-term parameters of model (1) using two cointegration regression methods Dynamic Ordinary Least Squares (DOLS) and Fully Modified Ordinary Least Squares (FMOLS), and two pooled and grouped panel methods. DOLS regression is used to avoid estimation problems related to autocorrelation, heteroskedasticity, and multi-collinearity, while FMOLS regression is used to avoid problems of normality of sample-related residues small, endogeneity of the independent variable. As for the panel methods, the Pooled estimation method assumes that the intercepts are homogeneous 
between the sections (the countries), whereas the Grouped estimate assumes that the intercepts are heterogeneous between the countries.

Table 3. Long-term Parameters Estimation

\begin{tabular}{|c|c|c|}
\hline Panel method & Grouped & Pooled \\
\hline DOLS & $0.00000000468 *$ & $0.000000000615^{*}$ \\
\hline FMOLS & $0.00000000217^{*}$ & $0.000000000357^{*}$ \\
\hline
\end{tabular}

Note: *,**,*** indicate significance respectively at the level of $1 \%, 5 \%$ and $10 \%$. The maximum delay selection is automatic by the software using the SIC as a benchmark.

All the estimations show that the FDI inflows have a positive impact on carbon emissions at level of significance of $1 \%$. In the case of Panel DOLS method with grouped version, an increase of 1 million \$US could result of 0,00468 metric tons of CO2 per capita while pooled version makes it 0.000615 metric tons of CO2 per capita. Using the Fully Model OLS admits, for grouped version, a raising of 1 million \$US in FDI inflows will be followed by 0.00217 metric tons of $\mathrm{CO} 2$ per capita increase, on the other hand, pooled version results an increase of 0,000357 metric tons of CO2 per capita.

\section{Estimating causality in Granger-Engle's sense}

The Engle-Granger test allows us to dynamically analyze the causality concluded previously between the two variables, i.e. separate between the short term and the long term. Knowing that the CE as the dependent variable and the FDI as the explanatory variable, it turns out that the long-term causality from FDI to CE is confirmed by the Engle Granger test since the value of $\boldsymbol{\varepsilon}_{\boldsymbol{t}-\mathbf{1}}$ is significant at the $1 \%$ threshold. Moreover, in the short term, the FDI has a positive impact on carbon dioxide emissions per capita at the significance level of $1 \%$.

Table 4. Granger-Engle's Causality Results

\begin{tabular}{|c|c|c|}
\hline \multirow{2}{*}{ Dependent variable } & \multicolumn{2}{|c|}{ Independent variable } \\
\cline { 2 - 3 } & $\Delta \boldsymbol{F D I}$ (Short term impact) & $\boldsymbol{\varepsilon}_{\boldsymbol{t}-\mathbf{1}}$ (long run impact) \\
\hline \multirow{2}{*}{$\Delta \boldsymbol{C E}$} & 0.000000000258 & -1.10767 \\
& $(0.00000)^{*}$ & $(0.00000)^{*}$ \\
\hline
\end{tabular}

Note: $* * *, * * *$ indicate significance respectively at the level of $1 \%, 5 \%$ and $10 \%$. The maximum delay selection is automatic by the software using the SIC as a benchmark.

\section{CONCLUSION}

In this paper, we have combined cross-sectional and time series data to examine the relationship between foreign direct investments inflows and carbon dioxide emissions in order to investigate the validity of the pollution haven hypothesis for the African countries over the period 1960-2018. We used the panel unit root test, and panel cointegration analysis to conclude that there is a long run causality running from foreign direct investments to $\mathrm{CO} 2$ emissions. Moreover, the DOLS and FMOLS results indicate that the FDI inflows have a positive impact on carbon dioxide emissions per capita. However, for the four versions of estimations, the calculated coefficients were slightly different, since we are examining the metric carbon dioxide emissions per capita, yet they are all positive and confirm the conclusions abovementioned. Therefore, our empirical results accept the pollution haven hypothesis for African countries. We also employed Granger-Engle causality test to examine the short-run and longrun causality between variables. The results show that the FDI inflows and carbon dioxide emissions have a positive causal relationship, for both short-run and long-run.

Furthermore, it is important to state that the factors behind the effects of foreign direct investment on carbon dioxide emissions are not explained through this result. Wherefore, 
future studies should include other variables into the FDI-CO2 nexus. African economies need to keep attracting the FDI inflows, alongside with strengthening their environmental policies and improving mechanisms and instruments for reducing $\mathrm{CO} 2$ emissions, such as environmental taxes, carbon capture and storage.

\section{References}

Akbostanci, Elif, G. İpek Tunç, and Serap Türüt-Aşik. 2007. "Pollution Haven Hypothesis and the Role of Dirty Industries in Turkey's Exports.” Environment and Development Economics 12 (2): 297-322.

https://doi.org/10.1017/S1355770X06003512.

Al-mulali, Usama, and Chor Foon Tang. 2013. "Investigating the Validity of Pollution Haven Hypothesis in the Gulf Cooperation Council (GCC) Countries." Energy Policy 60 (September): 813-19.

https://doi.org/10.1016/j.enpol.2013.05.055.

Ben Kheder, Sonia, and Natalia Zugravu-Soilita. 2008. "The Pollution Haven Hypothesis: A Geographic Economy Model in a Comparative Study." SSRN Scholarly Paper ID 1266705. Rochester, NY: Social Science Research Network. https://papers.ssrn.com/abstract=1266705.

Copeland, Brian R., and M. Scott Taylor. 1994. "North-South Trade and the Environment." The Quarterly Journal of Economics 109 (3): 755-87. https://doi.org/10.2307/2118421.

"EY's Attractiveness Program Africa 2019." n.d. Accessed November 14, 2019.

https://www.ey.com/za/en/issues/business-environment/ey-attractiveness-program-africa-2019.

Fadhil, Mohammed Ameen, and Mahmoud Khalid Almsafir. 2015. "The Role of FDI Inflows in Economic Growth in Malaysia (Time Series: 1975-2010)." Procedia Economics and Finance, 2nd GLOBAL CONFERENCE on BUSINESS, ECONOMICS, MANAGEMENT and TOURISM, 23 (January): 1558-66. https://doi.org/10.1016/S22125671(15)00498-0.

Javorcik, Beata Smarzynska, and Shang-Jin Wei. 2003. "Pollution Havens and Foreign Direct Investment: Dirty Secret or Popular Myth?" Contributions in Economic Analysis \& Policy 3 (2). https://doi.org/10.2202/15380645.1244.

Jbara '07, Brian W. 2007. "Exploring the Causality between the Pollution Haven Hypothesis and the Environmental Kuznets Curve." Honors Projects, January. https://digitalcommons.iwu.edu/econ_honproj/21.

Kirkpatrick, Colin, and Kenichi Shimamoto. 2008. "The Effect of Environmental Regulation on the Locational Choice of Japanese Foreign Direct Investment." Applied Economics 40 (11): 1399-1409. https://doi.org/10.1080/00036840600794330.

MacDermott, Raymond. 2009. "A Panel Study of the Pollution-Haven Hypothesis." Global Economy Journal 9 (1): 1850154. https://doi.org/10.2202/1524-5861.1372.

Melnyk, Leonid, Oleksandr Kubatko, and Sergiy Pysarenko. 2014. "The Impact of Foreign Direct Investment on Economic Growth: Case of Post Communism Transition Economies." Problems and Perspectives in Management 12 (January): 17-24.

Mutafoglu, Takvor H. 2012. "Foreign Direct Investment, Pollution, and Economic Growth: Evidence from Turkey." Journal of Developing Societies 28 (3): 281-97. https://doi.org/10.1177/0169796X12453780.

Omar, Wan Ahmad Wan, Fauzi Hussin, and Asan Ali G. H. 2015. "The Empirical Effects of Islam on Economic Development in Malaysia." Research in World Economy 6 (1): 99-111.

Porter, Michael E., and Claas van der Linde. 1995. "Toward a New Conception of the EnvironmentCompetitiveness Relationship." The Journal of Economic Perspectives 9 (4): 97-118.

Sapkota, Pratikshya, and Umesh Bastola. 2017. "Foreign Direct Investment, Income, and Environmental Pollution in Developing Countries: Panel Data Analysis of Latin America." Energy Economics 64 (May): 206-12. https://doi.org/10.1016/j.eneco.2017.04.001.

Sarkodie, Samuel Asumadu, and Vladimir Strezov. 2019. "Effect of Foreign Direct Investments, Economic Development and Energy Consumption on Greenhouse Gas Emissions in Developing Countries." Science of The Total Environment 646 (January): 862-71. https://doi.org/10.1016/j.scitotenv.2018.07.365.

Sharif, Suhail. 2014. "Foreign Direct Investment and Unemployment Reduction in Pakistan." IJER 5 (January).

Sokang, Khun. 2018. "The Impact of Foreign Direct Investment on the Economic Growth in Cambodia: Empirical Evidence." International Journal of Innovation and Economic Development 4 (5): 31-38. https://doi.org/10.18775/ijied.1849-7551-7020.2015.45.2003. 
Solarin, Sakiru Adebola, Usama Al-Mulali, Ibrahim Musah, and Ilhan Ozturk. 2017. "Investigating the Pollution Haven Hypothesis in Ghana: An Empirical Investigation." Energy 124 (April): 706-19.

https://doi.org/10.1016/j.energy.2017.02.089.

“UNCTAD | World Investment Report: Annex Tables." n.d. Accessed November 13, 2019.

https://unctad.org/en/Pages/DIAE/World\%20Investment\%20Report/Annex-Tables.aspx. 